\title{
Cause for the Occurrence of Freemartin and Its Influence on Livestock Reproductive Performance
}

\author{
Gelaye Gebisa \\ School of Animal and Range Sciences, College of Agriculture, Hawassa University, Ethiopia
}

\begin{abstract}
Livestock reproductive performance is a prerequisite for any successful livestock production program and it is depends up on the factors viz. parturition interval, ovarian activity, days open, fertility and age at first parturition, litter size and annual reproductive rate. However, the above mentioned factors are influenced directly or indirectly by the occurrence of freemartin animal within the flock or farm. The objective of this review was to organize the condensed information about the causes for the occurrence of freemartin, development and way of examining a freemartin animal and its influence on livestock reproductive performance. A freemartin is genetically female, but has many characteristics of a male. The ovaries of the freemartin do not develop correctly, and they remain very small, also the ovaries do not produce the hormones necessary to induce the behavioral signs of heat. The external vulvar region can range from a very normal looking female to a female that appears to be male. Usually, the vulva is normal except that in some animals an enlarged clitoris and large tufts of vulvar hair exist. It can be diagnosed in a number of ways ranging from simple examination of the placental membranes to chromosomal analysis. Understanding about the freemartin syndrome is important to take measure by the livestock keepers, farm managers or veterinarian to cull the heifer at her early age or keep it as a teaser bull and/or as draft animal.
\end{abstract}

Keywords: Freemartin; Livestock; Masculinization; Reproductive Performance

DOI: $10.7176 / \mathrm{JNSR} / 12-21-03$

Publication date: November $30^{\text {th }} 2021$

\section{Introduction}

Livestock reproductive performance is a prerequisite for any successful livestock production program and undoubtedly there is no milk if birth does not occur, no meat and fiber if survival can't be ensured [1]. Livestock management should always include some method to monitor continuously the reproductive performance of any herd or flock. Moreover comprehensive procedures for assessing efficiency should measure the total number of viable offspring produced by all mature females in the breeding unit over a suitable time period [2]. Reproductive performance of livestock depends on the following factors such as parturition interval, ovarian activity, days open, fertility and age at first parturition and also in case of small ruminant; litter size and annual reproductive rate are determines the measure of reproductive efficiency of the livestock. However, those factors have been influenced by one and another but freemartin is one of the factors that affect the reproductive performance of the livestock by affecting the fertility of the livestock. In mixed-sex twin pregnancies, an anastomosis of the placental blood vessels can occur; resulting in a common fetal circulation, likewise freemartinisim can be attributed to intersexuality [3]. Intersexes possess genital organs with both male and female characteristics and can be subdivided in to real "hermaphrodites" which have both male and female gonads and "pseudo male" or "pseudo female" hermaphrodites which have either male or female gonads combined with accessary genital organs of the other gender [4]. Moreover, freemartins arise when vascular connections form between the placentae of developing heterosexual twin fetus $\mathrm{XX} / \mathrm{XY}$ chimerism develops and ultimately there is masculinization of the female tubular reproductive tract to varying degrees and it occurring in twins of different sexes $[3,4]$. Freemartin in cow is a sterile female cow with confused sexual characteristics and which explains as couldn't able to bred and in fact not able to produce offspring. According to different report, out of all freemartin occurrences, ninety percent of them were from all male-female cows of total twins and occasionally in sheep, goats, and pigs [5]. Prevalence of the freemartin syndrome in cattle population is directly dependent of the prevalence of twinning within the population. Although congenital, freemartinism is not a heritable defect, and consequently does not directly respond to negative selection. However, twining seems to have some genetic background, and it has been found to present different incidence among breeds. Additionally, twinning incidence may vary with men-imposed artificial selection, either by culling or by intentionally use cows with higher twinning rates [6]. Freemartin in ewe is an infertile female sheep and they can have varying degrees of phenotypic masculinization; characteristics include narrowing of the vaginal channel, clitoris hypertrophy, mammary tissue hypoplasia and in some cases; presence of active male gonads and exhibition of male behaviors such as heat detection and aggressiveness [3]. Understanding the impacts of freemartin on the livestock farming is important to manage the farm according to the aim of keeping livestock in the farm. Organizing the information about freemartin could be an important document for taking an appropriate decision by livestock keepers, farm managers and veterinarians. Thus, the objectives of this review were to compile organized information about the main causes for the occurrence of freemartin, the development and way of examining a freemartin animal and its influence on livestock reproductive 
performance.

\section{Cause for occurrence of freemartin}

The main cause for occurrence of infertile females is mixed-sex twin pregnancies are chimeras, i.e. having two cell populations: one of their own (XX DNA) and one from their male twin (XY DNA) and it's occurred because of a blood fusion between two fetuses [3] and the blood carries all sorts of things throughout the bodies including hormones produced by the bull calf's gonads, i.e. influence the development of the heifer calf's sex organs [5]. Moreover, in mixed-sex twin pregnancies anastomosis of the placental blood vessels can occur and resulting in a common fetal circulation. This situation allows the anti-Mullerian hormone of the male embryo to reach the female embryo and promote atrophy of the paramesonephric duct (Mullerian duct), as well as promoting virilization of the structures derived from the mesonephric duct and it causes the freemartin condition in the female embryo. The incidence of freemartinism in goats is generally low $(<1 \%)$, increased risk has been observed when litter sizes are four or more. Other intersex phenotypes in goats can result from effects of the polled gene [7].

\section{Development of freemartin}

During embryonic development, there is a blood fusion between two fetuses and the blood carries all sorts of things throughout the bodies including hormones produced by the bull calf's gonads. Furthermore, in addition to hormones the two calves' share cells via the co-circulating blood and both twins become genetic mosaics also called chimeras. A genetic mosaic is an individual with two distinct sets of chromosomes. For instance, a normal cow has 60 different chromosomes in each cell. In contrast, freemartin cow has 60 chromosomes in each cell but some of the cells came from her brother, so the female calf actually has her original 60 chromosomes plus 60 different chromosomes in the cells she got from her brother and majority of the male cells are blood cells. Because the male cells in the freemartin are blood cells and they do not have much effect on her sexual organ development [5]. In case of cattle, a pregnant cow with two fetuses, the extraembryonic membranes of each fetus frequently fuse forming a common chorion, i.e. the outermost extraembryonic membrane and derived from the trophoblastic ectoderm and this will eventually attach to the uterus. Thus, both the male and female fetus shares the same cotyledons and the cotyledons which are distributed across the surface of the chorion it consists of many blood vessels and connective tissues. By sharing the same cotyledons, both the male and female fetus shares the same blood supply and this blood supply provide both the male and female twins with the same hormonal combination including testosterone and anti-Mullerian hormone [8]. As mentioned above in case of cattle, the fusion of the membranes generally occurs within 1 month of gestation which is right before sexual differentiation of the fetus takes place. The sexual differentiation of the testes occurs before the ovaries (recognizable at around 40 days) and the hormones produced by the testes work to inhibit the reproductive growth in the female fetus. The hormone that has a negative effect is anti-Mullerian hormone; it is a hormone produced by embryonic Sertoli cells in the male. This hormone causes the degeneration of the Mullerian ducts and it stops the growth of the paramesonephric ducts and also known as Mullerian ducts. Eventually it develops into the oviducts, uterus, cervix and portions of the vagina in the female fetus. Thus, the female heifer known as a freemartin heifer and it has an incomplete development of the reproductive tract. This includes the ovaries which are underdeveloped and are incapable of producing hormones such as estrogen, greatly reducing the femininity of this heifer [9].

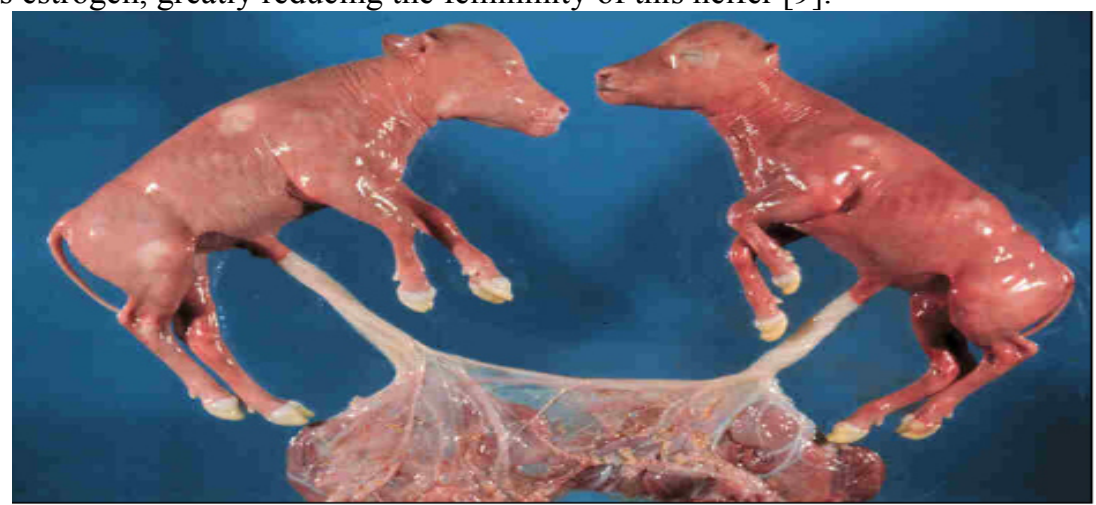

Source: http://www.uoguelph.ca/ rfoster/repropath/flfgpics.htm

\section{Diagnosis of Freemartin Animal}

A freemartin animal can be diagnosed viz. history of animal, anatomical and histologic analysis, chromosomal analysis and hormonal analysis. Among the listed methods of analysis; we more focus on the later three methods of diagnosis. 


\section{Anatomical analysis}

The clinical or anatomical examination of freemartin's ewes can have varying degrees of phenotypic masculinization including some cases that having active male gonads and exhibiting male behaviors such as heat detection and aggressiveness and also as the report revealed, morphological abnormality of the vulva, the presence of scrotal sacs, and a lack of mammary tissue development were noted. Moreover, on inspection of the vaginal channel, an extremely enlarged clitoris and resembling a penis were found [3]. In contrast to this, study by Szatkowska ., et al [10] revealed that no other structures were found that could have been identified as gamete transporting organs and no gonads were found from normal phenotype goat i.e with normally developed labia and clitoris as well as there was malformation of reproductive organ of the goat. In addition to this, he also found that as no gonads were detected due to a huge cyst $(30 \mathrm{~cm} \times 28 \mathrm{~cm})$ with two ducts exiting it, of which one resembled a spermatic cord also known as funiculus spermaticus, as indicated by a network of blood vessels that are characteristic for this organ, whereas the other was connected with the uterus horns [10].

\section{Chromosomal Analysis}

Chromosomal analysis is generally accompanied by cell chimaerism of erythrocytes and lymphocytes expressed by an occurrence of two genetically differing cell lines which is used in diagnosis of freemartinism [3, 11, 12, and 13]. A blood sample from the jugular vein is taken in a vacutainer tube with of heparin and peripheral blood lymphocytes are cultured under sterile conditions, using standard methodologies. In addition, a karyotype analysis is performing using conventional Giemsa stain to color the chromosomes. Thus, the male Y-chromosome is identified in a proportion of circulating white blood cells and most often, the chromosomal analysis is utilized because of its accuracy and early identification. The genetic test can be performed within days of birth, allowing the farmer to quickly and easily identify any sterile female cattle in his/her herd. One company, GenMARK (VitaTech Laboratories LLC), offers a molecular-based test that uses the polymerase chain reaction (PCR) technology to amplify two distinct bovine sex-specific DNA sequences from whole blood. The procedure involves nucleic acid extraction, amplification of two distinct bovine sex-specific genetic sequences using PCR and product detection. The PCR assay is highly specific and sensitive, providing high coefficients of accuracy and validity to test results. A positive test result indicates that "Y" chromosome specific genes have been successfully amplified from the sample and identifies the calf as a freemartin. A negative test result indicates that DNA, specific to the "Y" chromosome, has not been amplified from the sample. The only perceived drawback of this method of freemartin testing is that the ability to isolate and prepare good quality nucleic acid decreases with increasing age of the clinical sample. Therefore, the PCR assay is most sensitive when nucleic acid is isolated from fresh samples. Up to $95 \%$ of the freemartin's blood cells can be derived from its twin brother. Furthermore, these derived cells can be easily isolated and visualized in the freemartin tissue. Thus, researchers are able to investigate the capacity of hematopoietic stem cells to produce other tissues in addition to blood. The freemartin serves as such a perfect model for this type of experimental research because it takes away the need for unnecessary implantation, allowing scientists to analyze perfectly healthy and un-manipulated animals [8].

\section{Hormonal Analysis}

The second type of examination is that the hormonal analysis, in this examination the plasma testosterone is identified from blood sample in different time interval before and after a single intravenous injection of testosterone $\left(t_{0}\right)$ of $4500 \mathrm{IU}$ hCG to an animal. Then after the blood samples will be collected every 15 min in the first hour, every $30 \mathrm{~min}$ in the second hour and every two hours for the following 6 hours after injection. During the next three days, blood samples will be collected at 12 hours intervals. The plasma testosterone and progesterone concentrations will be analyzed by RIA [14].

\section{Influence of freemartin on livestock reproductive performance}

Freemartin has an influence on the reproductive performance of livestock by affecting the fertility of the animal and it has role for the conservation of animal genetic resource. The degree of masculinization is greater if the fusion occurs earlier in the pregnancy but about 10 percent of all cases no fusion takes place and the female remains fertile. The male twin is largely unaffected by the fusion, although the size of the testicles may be slightly reduced and it's associated with fertility, there may be some reduction in bull fertility [15]. Likewise, freemartin/pseudo hermaphrodite condition is one of the reasons for the reproductive failure of the ewes[16]. In contrast to this a freemartin animal can be used for estrous detection and draught purpose [4].

\section{Conclusion}

Livestock reproductive performance is a prerequisite for any successful livestock production program and it depends on different reproductive factors. These factors are directly or indirectly influenced by the occurrence of freemartin syndrome within the farm. A freemartin is genetically female, but has many characteristics of a male. The ovaries of the freemartin do not develop correctly, and they remain very small, also the ovaries do not produce 
the hormones necessary to induce the behavioral signs of heat. The external vulvar region can range from a very normal looking female to a female that appears to be male. Usually, the vulva is normal except that in some animals an enlarged clitoris and large tufts of vulvar hair exist. Freemartins arise when vascular connections form between the placentae of developing heterosexual twin fetus $\mathrm{XX} / \mathrm{XY}$ chimerism develops and ultimately there is masculinization of the female tubular reproductive tract to varying degrees and it occurring in twins of different sexes and a freemartin animal can be diagnosed through anatomical, chromosomal and hormonal analysis. It has direct or indirect influence on the reproductive performance of the animal through affecting the fertility of the animal. Understanding about the freemartin syndrome is important to take measure by the livestock keepers, farm managers or veterinarian to cull the heifer at early age or keep it as a teaser bull and/or draft animal.

\section{References}

1. "Measures of reproductive performance". Retrieved Nov 21/2019: (http://www.fao.org /wair docs/ilri/x5442e/x5442e06.htm)

2. "Measures of reproductive performance". Retrieved Nov 21/2019: (www.aps.uoguelph .ca/ gking /Ag 2350/measures.htm).

3. Gonella-Diaza AM., et al. "Abnormal position of lymph nodes in a freemartin sheep". Journal of Veterinary Medicine; Research and Report 3.1 (2012) 6.

4. Hawks J. "Prenatal influences on the lives of twins: fertility (2007)". Retrieved on Nov 20/2019: http://johnhawks.net/weblog/reviews/epigenetics/fetal_influences/male_co-twin_female_fecundit y 2007.html.

5. "World play freemartin". Retrieved on Nov 21/ 2019: http://www.doranna. net/ wordplay /index.php/2011/04/29/freemartin/

6. Gregory K.E., et al. "Genetic environmental parameters for ovulation rate, twinning rate, and weight traits in a cattle population selected for twinning”. J. Anim. Sci., 75(1997):1213-1222.

7. Padula A. M. "The freemartin syndrome: an update". Animal Reproduction Science 87(2005): 93-109.

8. "Genetic aspect of freemartins". Retrieved on Nov 21/2019: http://www.ansci.wisc.edu /jjp1/ansci_repro/misc/project_websites_07/wed07/Freemartin/genetic_aspects_of_freemartins\%20-\%20Fre emartin\%20Diagnosis.htm

9. "Development of freemartin". Retrieved on Nov 20/2019: http://www.ansci.wisc.edu /jjp1/ansci_repro/misc/project_websites_07/wed07/Freemartin/Development\%20of\%20Freemartins.htm).

10. Szatkowska I., et al. "Freemartinism: Three Cases in Goats". Acta Vet Brno 73 (2004): 375-378.

11. Zhang T., et al. "Diagnosis of freemartinism in cattle: the need for clinical and cytogenic evaluation". J Amer Vet Med Assoc 15(1994): 1672-5.

12. Justi A., et al. "Comparison of different methods for the diagnosis of freemartinism-blood group serology, cytology and polymerase chain reaction”. Deut Tierarztl Woch, 102(1995): 471-474.

13. "Ennis S., et al. "The diagnosis of freemartinism in cattle using sex-specific DNA sequences". Res Vet Sci 67.1 (1999):111-112.

14. Henry M., et al. "Clinical and Andropological aspect of the oestrus cycle in donkey (Equus asinus)" . Journal of Reproduction and Fertility 35.1(1987): 297-303.

15. Alexandra E., et al. Freemartinism in Cattle". In: Ruminants: Anatomy, Behavior and Diseases, Nova Science Publishers, Inc. 2012.

16. Paula I. Menzies. "Reviews on Factors Affecting Reproductive Performance of Sheep". Retrieved on Nov 28/2019: http://www.merckmanuals.com/vet/ management and nutrition /management_of_ reproduction sheep/factors affecting reproductive performance of sheep.html. 